\title{
Association between hospital mortality and inspiratory airway pressures in mechanically ventilated patients without acute respiratory distress syndrome: a prospective cohort study
}

Sarina K. Sahetya', Christopher Mallow', Jonathan E. Sevransky², Greg S. Martin²,3 Timothy D. Girard", Roy G. Brower ${ }^{1}$, William Checkley ${ }^{* *}$ (D) and Society of Critical Care Medicine Discovery Network Critical Illness

Outcomes Study Investigators

\begin{abstract}
Background: Higher inspiratory airway pressures are associated with worse outcomes in mechanically ventilated patients with the acute respiratory distress syndrome (ARDS). This relationship, however, has not been well investigated in patients without ARDS. We hypothesized that higher driving pressures $(\Delta P)$ and plateau pressures (Pplat) are associated with worse patient-centered outcomes in mechanically ventilated patients without ARDS as well as those with ARDS.
\end{abstract}

Methods: Using data collected during a prospective, observational cohort study of 6179 critically ill participants enrolled in 59 ICUs across the USA, we used multivariable logistic regression to determine whether $\Delta P$ and Pplat at enrollment were associated with hospital mortality among 1132 mechanically ventilated participants. We stratified analyses by ARDS status.

Results: Participants without ARDS $(n=822)$ had lower average severity of illness scores and lower hospital mortality ( $27.3 \%$ vs. 38.7\%; $p<0.001$ ) than those with ARDS ( $n=310$ ). Average Pplat ( 20.6 vs. $23.9 \mathrm{~cm} \mathrm{H}_{2} \mathrm{O}$; $p<0.001), \Delta \mathrm{P}\left(14.3\right.$ vs. $16.0 \mathrm{~cm} \mathrm{H}_{2} \mathrm{O} ; p<0.001$ ), and positive end-expiratory pressure (6.3 vs. $\left.7.9 \mathrm{~cm} \mathrm{H}_{2} \mathrm{O} ; p<0.001\right)$ were lower in participants without ARDS, whereas average tidal volumes $(7.2 \mathrm{vs} .6 .8 \mathrm{~mL} / \mathrm{kg} \mathrm{PBW} ; p<0.001)$ were higher. Among those without ARDS, higher $\Delta \mathrm{P}$ (adjusted $\mathrm{OR}=1.36$ per $7 \mathrm{~cm} \mathrm{H}_{2} \mathrm{O}, 95 \% \mathrm{Cl}$ 1.14-1.62) and Pplat (adjusted $\mathrm{OR}=1.42$ per $8 \mathrm{~cm} \mathrm{H} \mathrm{H}_{2} \mathrm{O}, 95 \% \mathrm{Cl}$ 1.17-1.73) were associated with higher mortality. We found similar relationships with mortality among those participants with ARDS.

Conclusions: Higher $\Delta \mathrm{P}$ and Pplat are associated with increased mortality for participants without ARDS. $\triangle \mathrm{P}$ may be a viable target for lung-protective ventilation in all mechanically ventilated patients.

Keywords: Driving pressure, Mechanical ventilation, Acute respiratory failure, ARDS

\footnotetext{
*Correspondence: wcheckl1@jhmi.edu

'Division of Pulmonary and Critical Care, Johns Hopkins University, $1830 \mathrm{E}$

Monument St Room 555, Baltimore, MD 21287, USA

Full list of author information is available at the end of the article
}

(c) The Author(s). 2019 Open Access This article is distributed under the terms of the Creative Commons Attribution 4.0 International License (http://creativecommons.org/licenses/by/4.0/), which permits unrestricted use, distribution, and reproduction in any medium, provided you give appropriate credit to the original author(s) and the source, provide a link to the Creative Commons license, and indicate if changes were made. The Creative Commons Public Domain Dedication waiver (http://creativecommons.org/publicdomain/zero/1.0/) applies to the data made available in this article, unless otherwise stated. 


\section{Background}

Mechanical ventilation can increase survival rates of patients with acute respiratory failure. This life-saving technology, however, may also contribute to or worsen underlying lung injury through alveolar overdistention or repetitive opening and closing of small bronchioles and alveoli $[1,2]$. In patients with acute respiratory distress syndrome (ARDS), a lung-protective ventilation strategy aimed at preventing overdistention injury by limiting tidal volumes and plateau pressures (Pplat) improves survival and is therefore recommended in clinical practice guidelines $[3,4]$. Although these guidelines are frequently extrapolated to mechanically ventilated patients without ARDS, little evidence exists regarding the best ventilatory strategies for patients without ARDS.

Recently, driving pressure $(\Delta \mathrm{P})$ emerged as a potential target for optimizing mechanical ventilation to improve outcomes for ARDS patients. $\triangle \mathrm{P}$ is calculated as the difference between Pplat and positive end-expiratory pressure (PEEP) and is determined by the ratio of the tidal volume to the compliance of the respiratory system $\left(\triangle \mathrm{P}=\right.$ Pplat $\left.-\mathrm{PEEP}=\mathrm{V}_{\mathrm{T}} / \mathrm{C}_{\mathrm{RS}}\right)$. In patients with $\mathrm{ARDS}$, lower $\Delta \mathrm{P}$ has been associated with lower mortality in multiple studies and may be a critical mediator for the benefits of lung-protective ventilation strategies [5-8]. In patients without ARDS, lower $\triangle \mathrm{P}$ was associated in one study with a decreased risk of postoperative pulmonary complications for patients with normal lungs [9]. However, studies evaluating the relationship between airway pressures and mortality in patients without ARDS are few and demonstrate inconsistent results [9-11].

Inspiratory airway pressures (Pplat and $\Delta \mathrm{P}$ ) are utilized as surrogates for lung stress during mechanical ventilation, and high levels of stress applied to the lung may be injurious even in patients who do not have ARDS. We hypothesized that higher $\Delta \mathrm{P}$ and Pplat are associated with higher hospital mortality in non-ARDS patients as well as ARDS patients. To evaluate these relationships, we performed a secondary analysis of a large multicenter, prospective observational cohort of critically ill patients in the USA.

\section{Methods}

\section{Study design}

The Society of Critical Care Medicine (SCCM) Discovery Network Critical Illness Outcomes Study (CIOS) was a multicenter, prospective, observational cohort study of patients admitted to intensive care units (ICUs) in the USA. The content and protocol of this study have been previously described [12]. Eligibility criteria included adults $\geq 18$ years of age physically occupying a bed at 8 a.m. in a participating ICU. Participants were enrolled in the cohort between November 2008 and January 2012 across 59 ICUs in the USA. Participating sites enrolled all patients in the ICU during one assigned day per week. Enrollment days were chosen randomly, with 510 days between enrollments to allow for patient turnover. Patients in the ICU who were present during prior enrollment days were not enrolled a second time. Due to this recruitment strategy, baseline participant data were recorded from the day of enrollment into this study rather than the first day of mechanical ventilation. Participants were enrolled from three different types of ICU: medical, surgical, and mixed medical-surgical. Data were prospectively recorded in detail including ICU structure and process variables, patient demographics, ventilator settings, and severity scores including APACHE II scores. Participants were followed until hospital discharge. The primary outcome measure for the CIOS study was hospital mortality. Secondary outcomes included duration of mechanical ventilation and duration of intensive care unit and hospital stay. The CIOS study was approved by the Institutional Review Boards at all participating hospitals (NA_00026710).

We analyzed all participants receiving mechanical ventilation on the day of enrollment into the cohort except for those who were missing measurements of Pplat, PEEP, or ARDS status. ARDS status on day of enrollment was based on the American European Consensus Conference (AECC) definition [13]. The primary exposure variable was $\triangle \mathrm{P}$ on the day of enrollment into the study [5]. Daily ventilator settings were recorded at 8 a.m. on the day of enrollment. Ventilator pressures were collected on participants at the time of enrollment. $\triangle \mathrm{P}$ was calculated as Pplat minus PEEP. Set PEEP was directly recorded from the ventilator. Pplat was measured by a minimum $0.5 \mathrm{~s}$ inspiratory hold maneuver at zero flow in participants on volume-controlled ventilation or as an estimation from the observed peak inspiratory pressure (PIP) in participants on pressure-controlled modes. We included participants on spontaneous breathing modes of ventilation such as pressure support given recent literature suggesting that Pplat and $\Delta \mathrm{P}$ may be reliably estimated in the presence of spontaneous breathing [14, 15]. A sensitivity analysis evaluating the effect of including participants on spontaneous mode of ventilation was performed as described below. We excluded participants with biologically implausible values for Pplat, such as those with Pplat less than PEEP or with Pplat $\leq 5 \mathrm{~cm} \mathrm{H}_{2} \mathrm{O}$. The primary outcome was mortality at hospital discharge.

\section{Biostatistical methods}

The primary objective was to evaluate the relationship between inspiratory airway pressures (Pplat and $\Delta \mathrm{P}$ ) and hospital mortality in participants without ARDS and to compare the relationship in participants with ARDS. We estimated the association between hospital mortality and 
inspiratory airway pressures (Pplat and $\Delta \mathrm{P}$ ) with multivariable logistic regression and used general estimating equations with a compound symmetry matrix and a robust variance to account for ICU-level clustering. For the multivariable analysis, we identified covariates that may be associated with mortality, could influence ventilator management, and were not collinear with $\Delta \mathrm{P}$. We did not include tidal volume or respiratory system compliance in regression models containing $\Delta \mathrm{P}$ given concerns for collinearity as $\Delta \mathrm{P}$ is determined by the ratio of tidal volume to compliance. Individual covariates included sex, age, Acute Physiology and Chronic Health Evaluation II (APACHE II) score, need for vasopressors, presence of sepsis, and PEEP at time of enrollment. ICU level covariates included type of ICU (medical, surgical, or mixed) and hospital volume (categorized as $<25,000$, $25,000-39,999$, or $>40,000$ admissions per year). Odds ratios (OR) were scaled to the interquartile range (IQR) of the analyzed airway pressure.

We performed a secondary analysis evaluating Pplat as the primary exposure variable rather than $\Delta \mathrm{P}$. We evaluated this model to determine if both inspiratory airway pressures were associated with mortality for participants with acute respiratory failure regardless of ARDS status. We tested interactions between inspiratory airway pressures and ARDS status as well as inspiratory airway pressures and $\mathrm{PaO} 2 / \mathrm{FiO} 2$ ratio using cross-product terms (e.g., $\triangle \mathrm{P} \times \mathrm{ARDS}$ status), and used the likelihood ratio test to determine if including the cross-product term improved the model fit.

Multiple sensitivity analyses were conducted to evaluate the robustness of our results. First, we restricted the analysis to participants with Pplat less than $35 \mathrm{~cm} \mathrm{H}_{2} \mathrm{O}$ to determine if our results were robust to participants without outlying Pplat and $\Delta \mathrm{P}$ measurements. Second, we conducted a sensitivity analysis where we restricted our data to participants with PEEP $\geq 5 \mathrm{~cm} \mathrm{H}_{2} \mathrm{O}$. Third, we evaluated if the association between $\Delta \mathrm{P}$ and hospital mortality was primarily related to the presence of hypoxemic respiratory failure $\left(\mathrm{PaO}_{2} / \mathrm{FiO}_{2}<300 \mathrm{mmHg}\right)$ in non-ARDS participants. Finally, we limited the analysis to participants on controlled mechanical ventilation modes (i.e., volume control, pressure control, synchronized intermittent mandatory ventilation, pressure-regulated volume control) to determine if including participants on spontaneous modes affected the results. Participants with missing data in either the primary outcome or the primary exposures were excluded from multivariable analysis. Missing data for included variables in our sample population of mechanically ventilated participants were less than $3 \%$ and were assumed to be missing at random.

For other analyses, continuous variables are presented as means (standard deviation) if normally distributed and medians (interquartile range) if non-normally distributed.
Categorical variables are presented as counts $(n)$ and percentages. Comparisons between variables were conducted using the Student $t$ test for continuous variables, and the Pearson chi squared or Fisher's exact test for categorical variables. We conducted statistical analyses in R (www.r-project. org) and STATA version 14.0 (College Station, TX). We analyzed and reported this study according to the Strengthening the Reporting of Observational Studies in Epidemiology (STROBE) guidelines.

\section{Results}

\section{Participant characteristics}

We enrolled 2513 mechanically ventilated participants from November 2008 until January 2012 in 59 ICUs. Of these participants, 1132 were eligible for analysis in our study (Fig. 1). Of these, 822 (72.6\%) did not have ARDS and $310(27.4 \%)$ had ARDS. Baseline characteristics of participants with and without ARDS were mostly similar (Table 1). However, participants without ARDS had lower severity of illness based on APACHE II (20.2 vs. 22.1 ) and SOFA scores (6.6 vs. 8.3 points). The primary reason for ICU admission was for a respiratory indication (non-ARDS 50\% vs. ARDS 74\%) with a high proportion of pneumonia in both groups (non-ARDS $30.4 \%$ vs. ARDS 47.4\%). Mortality was lower in the non-ARDS group (27.3\%) versus the ARDS group (38.7\%).

Average Pplat and $\triangle \mathrm{P}$ were lower in participants without ARDS (Pplat 20.6 vs. $23.9 \mathrm{~cm} \mathrm{H}_{2} \mathrm{O}, p<0.001$; and $\Delta \mathrm{P} 14.3$ vs. $\left.16.0 \mathrm{~cm} \mathrm{H}_{2} \mathrm{O}, p<0.001\right)$ as compared to those with ARDS (Fig. 2). Non-ARDS participants received significantly higher tidal volumes (7.2 vs. 6.8 $\mathrm{mL} / \mathrm{kg}$ predicted body weight (PBW); $p<0.001)$ and significantly lower PEEP (5 vs. $7 \mathrm{~cm} \mathrm{H}_{2} \mathrm{O} ; p<0.001$ ) than ARDS participants (Fig. 3).

There were more participants enrolled from medical ICUs $(n=539)$ compared to the surgical $(n=298)$ or mixed ICUs $(n=295)$. Participants in the medical ICUs received significantly lower tidal volumes per kilogram PBW compared to the surgical and mixed ICUs (see Additional file 1: Table S1). However, there were no differences in $\Delta \mathrm{P}$ or Pplat between types of ICUs. Participants in surgical ICUs had higher days on mechanical ventilation and length of stay; however, they had lower mortality rates.

\section{Ventilator pressures and mortality}

In unadjusted and adjusted analyses, $\Delta \mathrm{P}$ was independently associated with hospital mortality in both non-ARDS and ARDS participants. After adjusting for covariates, nonARDS participants demonstrated an increased odds of hospital mortality per IQR increment of $\Delta \mathrm{P}$ (adjusted $\mathrm{OR}=1.36$ per $\left.7 \mathrm{~cm} \mathrm{H}_{2} \mathrm{O}, 95 \% \mathrm{CI} 1.14-1.62\right)$ and per IQR increment of Pplat (adjusted $\mathrm{OR}=1.42$ per $8 \mathrm{~cm} \mathrm{H}_{2} \mathrm{O}, 95 \%$ CI 1.17-1.73) (Table 2). Similarly, ARDS participants demonstrated an 


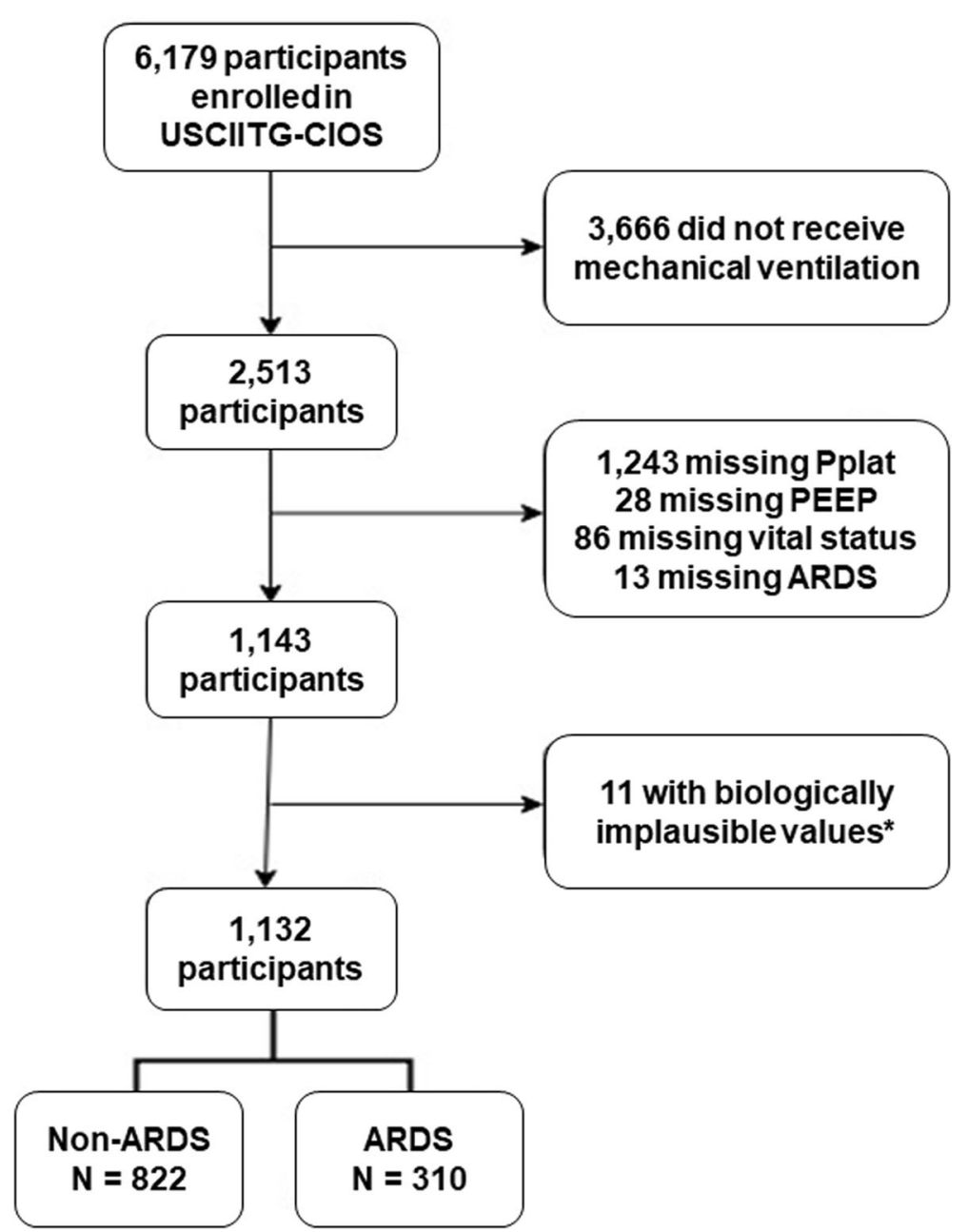

Fig. 1 Flowchart of participants included in analysis. *Biologically implausible values defined as plateau pressure less than PEEP $(n=5)$ or plateau pressure less than $5 \mathrm{~cm} \mathrm{H}_{2} \mathrm{O}(n=6)$

increased odds of mortality per IQR increment of $\Delta \mathrm{P}$ (adjusted $\mathrm{OR}=1.63$ per $\left.7 \mathrm{~cm} \mathrm{H}_{2} \mathrm{O}, 95 \% \mathrm{CI} 1.22-2.16\right)$ and Pplat (adjusted $\mathrm{OR}=1.74$ per $8 \mathrm{~cm} \mathrm{H}_{2} \mathrm{O}, 95 \%$ CI 1.26-2.41) (Fig. 4). Higher APACHE II scores were also associated with mortality in both populations, while use of vasopressors was associated with mortality only in participants without ARDS. The presence of sepsis, hospital volume, and type of ICU were not associated with survival in either group.

\section{Sensitivity analyses}

There were no significant interaction effects between $\Delta \mathrm{P}$ and ARDS status ( $p=0.32$ from likelihood ratio test) or between Pplat and ARDS status ( $p=0.13$ from likelihood ratio test) on hospital mortality. Our results were robust to restricting the range of Pplat to less than $35 \mathrm{~cm} \mathrm{H}_{2} \mathrm{O}$, and $\Delta \mathrm{P}$ remained independently associated with hospital mortality in non-ARDS participants in this population. Similarly, $\Delta \mathrm{P}$ remained independently associated with hospital mortality in non-ARDS participants when we excluded participants with PEEP $<5 \mathrm{~cm} \mathrm{H}_{2} \mathrm{O} \quad(n=4)$. Our results were also robust to restricting the participant population to those on controlled modes of ventilation (see Additional file 1: Tables S2, S3, and S4). We were unable to fully assess for interactions between airway pressures and the presence of spontaneous breathing as we did not have information on the actual total respiratory rate compared to the set respiratory rate of patients on controlled modes of ventilation. Finally, $\Delta \mathrm{P}$ remained independently associated with hospital mortality in non-ARDS participants in both hypoxemic respiratory failure $(\mathrm{PF}<300 \mathrm{mmHg}$, adjusted $\mathrm{OR}=1.41$, 95\% CI 1.08-1.84 per $7 \mathrm{cmH}_{2} \mathrm{O}$ ) and non-hypoxemic respiratory failure $(\mathrm{PF} \geq 300 \mathrm{mmHg}$, adjusted $\mathrm{OR}=1.38$ per $\left.7 \mathrm{cmH}_{2} \mathrm{O}, 95 \% \mathrm{CI} 1.08-1.75\right)$.

\section{Discussion}

The results of this study suggest that monitoring and potentially limiting inspiratory airway pressures is important 
Table 1 Baseline characteristics of non-ARDS and ARDS participants

\begin{tabular}{|c|c|c|c|}
\hline & Non-ARDS $(n=822)$ & ARDS $(n=310)$ & $p$ value \\
\hline Age (years) & $60.3(16.6)$ & $59.1(15.9)$ & 0.23 \\
\hline Male & $440(53.5)$ & $170(54.8)$ & 0.69 \\
\hline African-American & $209(25.4)$ & $61(19.7)$ & 0.04 \\
\hline Medical ICU & $375(45.6)$ & $164(52.9)$ & $<0.001$ \\
\hline \multicolumn{4}{|l|}{ Initial admitting diagnosis ${ }^{\mathrm{a}}$} \\
\hline Respiratory & $416(50.6)$ & $230(74.2)$ & $<0.001$ \\
\hline Neurological & $251(30.5)$ & $48(15.5)$ & $<0.001$ \\
\hline Cardiovascular & $226(27.5)$ & $84(27.1)$ & 0.89 \\
\hline Infectious & $221(26.9)$ & $138(44.5)$ & $<0.001$ \\
\hline Gastrointestinal & $122(14.8)$ & $44(14.2)$ & 0.78 \\
\hline Trauma & $61(7.4)$ & $9(2.9)$ & 0.005 \\
\hline Endocrine & $38(4.6)$ & $12(3.9)$ & 0.58 \\
\hline Other & $134(16.3)$ & $37(11.9)$ & 0.067 \\
\hline Sepsis & $261(31.8)$ & $190(61.7)$ & $<0.001$ \\
\hline Pneumonia & $250(30.4)$ & $148(47.7)$ & $<0.001$ \\
\hline APACHE $\|$ & $20.2(7.4)$ & $22.1(7.7)$ & $<0.001$ \\
\hline SOFA & $6(4-9)$ & $8(5-11)$ & $<0.001$ \\
\hline $\mathrm{PaO}_{2} / \mathrm{FiO}_{2}$ & $255.6(150.7)$ & $174.8(102.3)$ & $<0.001$ \\
\hline Compliance respiratory system & $39.6(28.2)$ & $35.1(35.6)$ & 0.04 \\
\hline Plateau pressure & $20.6(6.5)$ & $23.9(7.1)$ & $<0.001$ \\
\hline Driving pressure & $14.3(6.0)$ & $16.0(6.4)$ & $<0.001$ \\
\hline PEEP & $5(5-8)$ & $7(5-10)$ & $<0.001$ \\
\hline Tidal volume (mL/kg PBW) & $7.2(1.21)$ & $6.78(1.19)$ & $<0.001$ \\
\hline Hospital LOS & $18(10-30)$ & $19(10-33)$ & 0.43 \\
\hline ICU LOS & $10(5-17)$ & $11(6-18)$ & 0.04 \\
\hline Ventilator days & $7(3-14)$ & $9(5-15)$ & 0.01 \\
\hline Mortality & $224(27.3)$ & $120(38.7)$ & $<0.001$ \\
\hline
\end{tabular}

Abbreviations: ARDS acute respiratory distress syndrome, APACHE Acute Physiologic and Chronic Health Evaluation, SOFA Sequential Organ Failure Assessment, ICU intensive care unit, PEEP positive end-expiratory pressure, $P B W$ predicted body weight, LOS length of stay

Data presented as mean (SD), median (IQR), or $n(\%)$

${ }^{a}$ May have more than one admitting diagnosis. Does not sum to $100 \%$

for all mechanically ventilated patients, not just patients with ARDS. In our multicenter prospective observational cohort, we demonstrate that inspiratory airway pressures were independently associated with hospital mortality in a cohort of non-ARDS participants requiring mechanical ventilation. We also confirm the previously reported association between inspiratory airway pressures and mortality in ARDS participants $[5-8,16,17]$. Our results are consistent with prior meta-analyses and epidemiologic studies demonstrating improved outcomes from low versus higher tidal volume ventilation and lower $\Delta \mathrm{P}$ and Pplat in patients without ARDS $[9,18-20]$. In our study, tidal volumes on average at time of study enrollment were within the target range of $6-8 \mathrm{~mL} / \mathrm{kg} \mathrm{PBW}$ [4]. Even within this range of tidal volumes, however, lower $\Delta \mathrm{P}$ was associated with increased survival.
Our results suggest that higher $\Delta \mathrm{P}$ and Pplat reflect potentially injurious stresses on the lungs of non-ARDS patients that are associated with higher odds of mortality. $\Delta \mathrm{P}$ is determined by the distribution of a tidal volume across the available aerated lung (represented by respiratory system compliance). Patients without ARDS may benefit from reductions in $\Delta \mathrm{P}$ to prevent or mitigate ventilator-induced lung injury. For example, patients with unilateral pneumonia will have a heterogeneous distribution of tidal volume based on the reduced volume of aerated lung. Increased $\Delta \mathrm{P}$ in this type of patient may indicate the need for further reductions in tidal volume to prevent overdistention of the unilaterally aerated lung. Similarly, patients with obstructive airways disease may have a heterogeneous distribution of tidal volume and differences in regional transpulmonary pressures due to 


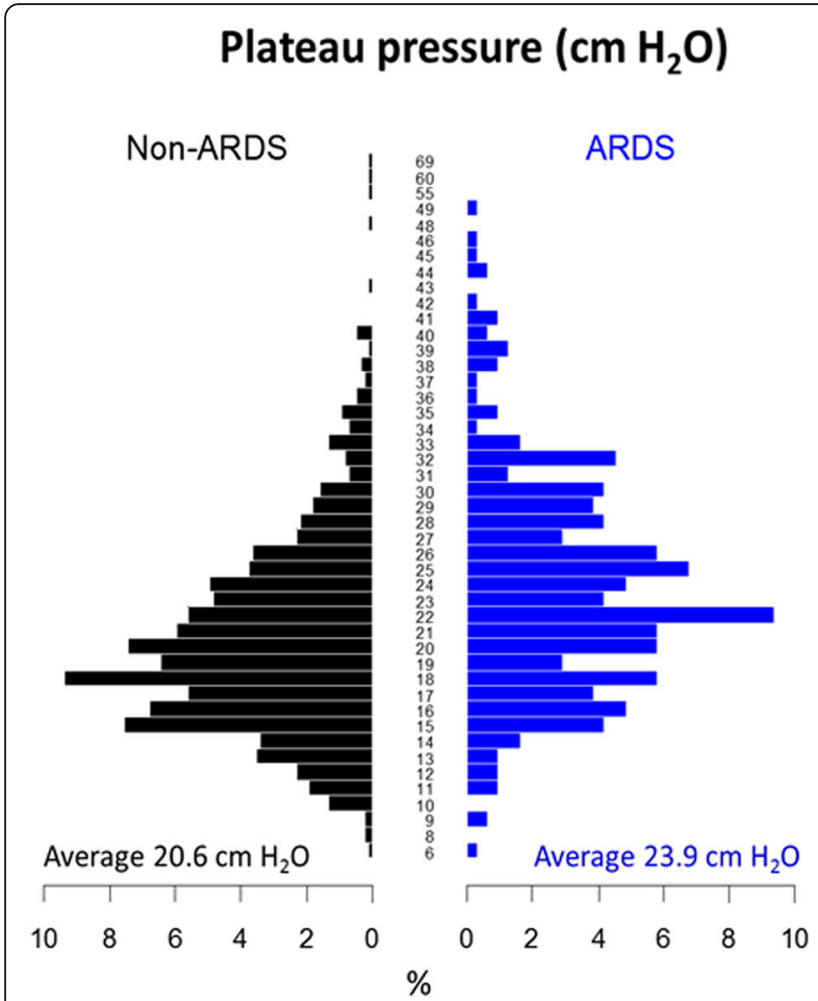

\section{Driving pressure $\left(\mathrm{cm} \mathrm{H}_{2} \mathrm{O}\right)$}
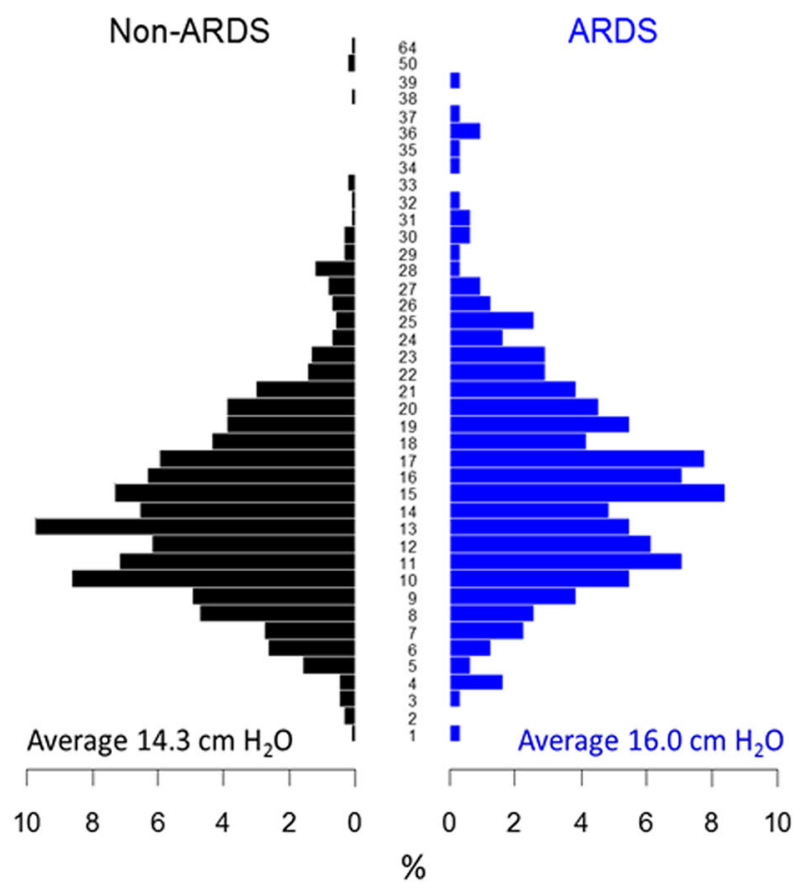

Fig. 2 Distribution and average Pplat and $\Delta P$ by ARDS status. ${ }^{*} p$ value for the difference in plateau pressure and ARDS status is $<0.001 .{ }^{* *} p$ value for the difference in driving pressure and ARDS status is $<0.001$

variations in emptying time of different lung regions (i.e., time constant). In these patients, changes in $\Delta \mathrm{P}$ could provide information on the influence of different PEEP levels on airflow limitations. Thus, even without the diagnosis of ARDS, $\triangle \mathrm{P}$ may convey important clinical and prognostic information for the patient with acute respiratory failure. Additionally, even patients without a primary lung disease may benefit from limiting $\Delta \mathrm{P}$. Neto and colleagues demonstrated an increased risk of postoperative complications with higher $\Delta \mathrm{P}$ in patients with normal lungs undergoing surgery [9]. We suggest future clinical trials evaluate whether implementing lung-protective ventilation strategies to limit $\Delta \mathrm{P}$ increases survival for all mechanically ventilated patients, with or without ARDS.

In contrast, a recent retrospective study by Schmidt and colleagues suggested that $\Delta \mathrm{P}$ was not associated with mortality in non-ARDS patients [10]. Although their study was similarly powered to ours, it was a single-center cohort and ARDS status was ascertained retrospectively. Furthermore, they had with a limited range of Pplat and PEEP, which may have attenuated the association between $\Delta \mathrm{P}$ and mortality in their study. In our study, the non-ARDS participants had a wider range of $\Delta \mathrm{P}$ (interquartile range 10-17 $\left.\mathrm{CmH}_{2} \mathrm{O}\right)$ and lower respiratory system compliance $(39.6 \mathrm{~L} /$ $\mathrm{CmH}_{2} \mathrm{O}$ ) compared to the participants in the Schmidt study [10]. Additionally, the Schmidt study included a non-ARDS study population with a low incidence of a pulmonary indication for ICU admission. Their sample had a $4 \%$ incidence of pneumonia. In our study, $50.6 \%$ of participants had an initial ICU admitting diagnosis related to the respiratory system, with a $30.4 \%$ incidence pneumonia. It is possible that the higher incidence of primary lung pathology and subsequent increased risk for ventilator-induced lung injury in our study, as well as the broader range of $\Delta \mathrm{P}$ and Pplat, improved the power of our study to identify a significant relationship between $\Delta \mathrm{P}$ and mortality.

Recently, the PReVENT trial investigated a low tidal volume (goal $6 \mathrm{~mL} / \mathrm{kg} \mathrm{PBW}$ ) versus an intermediate tidal volume (goal $10 \mathrm{cc} / \mathrm{kg} \mathrm{PBW}$ ) in patients without ARDS. The investigators failed to find a difference in patient outcomes between a low and intermediate tidal volume strategy in non-ARDS patients [18]. However, in this study, baseline $\Delta \mathrm{P}$ in both groups was relatively low and changed minimally with the tidal volume intervention (low tidal volume group baseline to day $1 \Delta \mathrm{P}, 11$ to 10 $\mathrm{cmH}_{2} \mathrm{O}$; intermediate tidal volume group baseline to day $1 \Delta \mathrm{P}, 13$ to $13 \mathrm{cmH}_{2} \mathrm{O}$ ). Consistent with the mediation analysis performed by Amato and colleagues [5], the change in driving pressure may be more important than the change in tidal volume in terms of reducing mortality in mechanically ventilated patients. Additionally, by day 1 following randomization, a majority of participants 

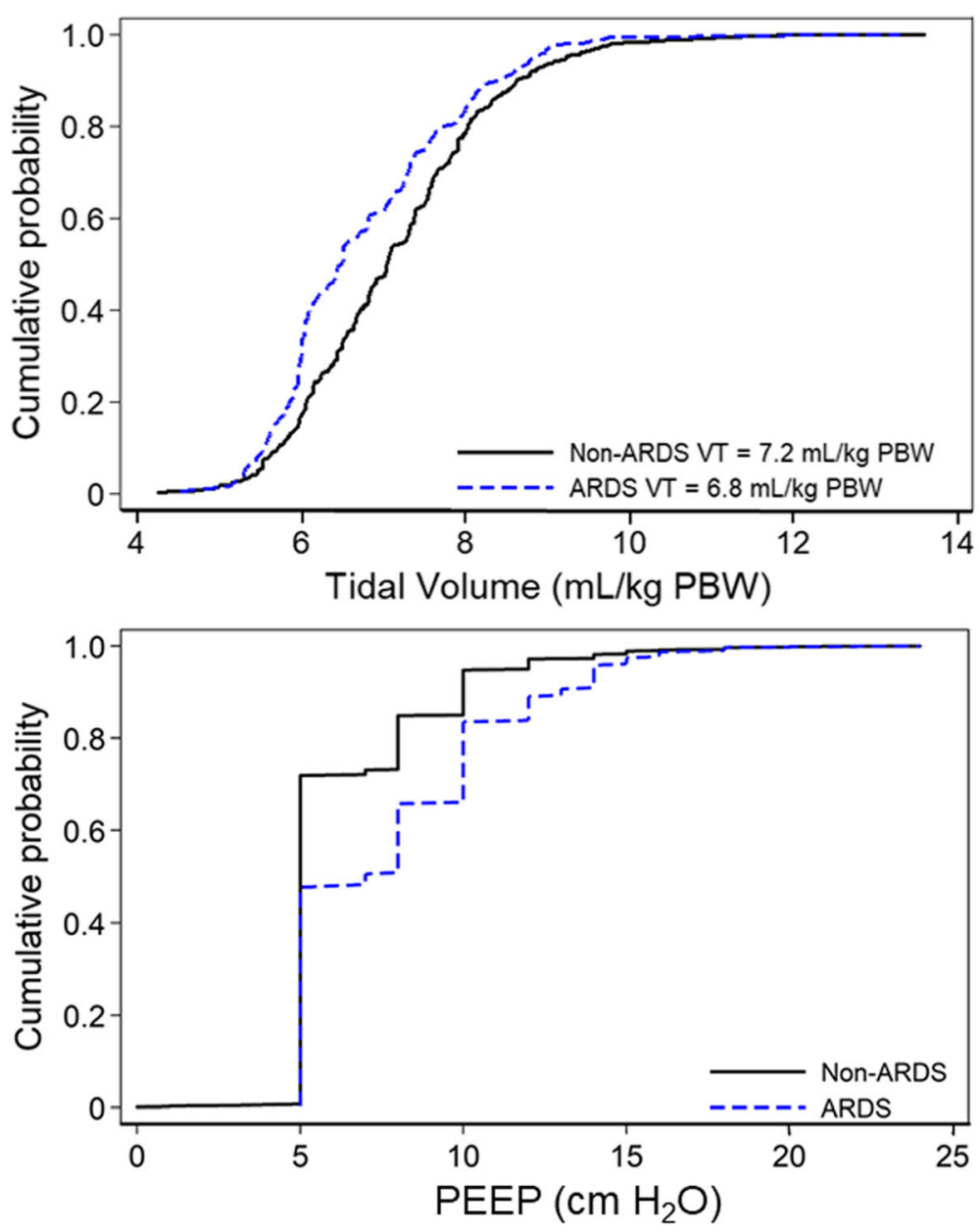

Fig. 3 Cumulative distribution of tidal volume and PEEP by ARDS status. ${ }^{*} p$ value for a difference in means of tidal volume for ARDS vs. nonARDS is $<0.001 .{ }^{* *} p$ value for a difference in means of PEEP for ARDS vs. non-ARDS is $<0.001$

Table 2 Odds of hospital mortality from multivariable logistic regression

\begin{tabular}{|c|c|c|c|c|c|c|}
\hline & \multicolumn{3}{|c|}{ Non-ARDS } & \multicolumn{3}{|c|}{ ARDS } \\
\hline & $\overline{\mathrm{OR}^{a}}$ & $95 \% \mathrm{Cl}$ & $\overline{p \text { value }}$ & $\overline{\mathrm{OR}^{\mathrm{a}}}$ & $95 \% \mathrm{Cl}$ & $\overline{p \text { value }}$ \\
\hline Driving pressure (per $7 \mathrm{~cm} \mathrm{H} \mathrm{H}_{2} \mathrm{O}$ ) & 1.36 & $1.14-1.62$ & $<0.001$ & 1.63 & $1.22-2.16$ & $<0.001$ \\
\hline Plateau pressure $\left(\text { per } 8 \mathrm{~cm} \mathrm{H}_{2} \mathrm{O}\right)^{\mathrm{b}}$ & 1.42 & $1.17-1.73$ & $<0.001$ & 1.74 & $1.26-2.41$ & $<0.001$ \\
\hline Age (per 5 years) & 1.05 & $0.98-1.11$ & 0.125 & 1.09 & $0.99-1.20$ & 0.07 \\
\hline PEEP (per $1 \mathrm{~cm} \mathrm{H}{ }_{2} \mathrm{O}$ ) & 1.05 & $0.98-1.11$ & 0.16 & 1.12 & $1.07-1.17$ & $<0.001$ \\
\hline APACHE ॥ (per 1 point) & 1.08 & $1.04-1.11$ & $<0.001$ & 1.08 & $1.04-1.12$ & $<0.001$ \\
\hline Vasopressor use & 1.52 & $1.06-2.16$ & 0.02 & 1.02 & $0.56-1.85$ & 0.94 \\
\hline Sepsis & 1.12 & $0.77-1.62$ & 0.56 & 1.03 & $0.62-1.69$ & 0.90 \\
\hline
\end{tabular}

Abbreviations: ARDS acute respiratory distress syndrome, APACHE Acute Physiologic and Chronic Health Evaluation, PEEP positive end-expiratory pressure, OR odds ratio

Estimates for covariates are derived from the driving pressure model. The plateau pressure model included the same covariates as the driving pressure model ${ }^{a}$ Odds ratio adjusted for age, sex, PEEP, APACHE II, vasopressor use, sepsis, hospital volume, and ICU category

${ }^{\mathrm{b}}$ Odds ratios for driving pressure and plateau pressure are scaled to IQRs 

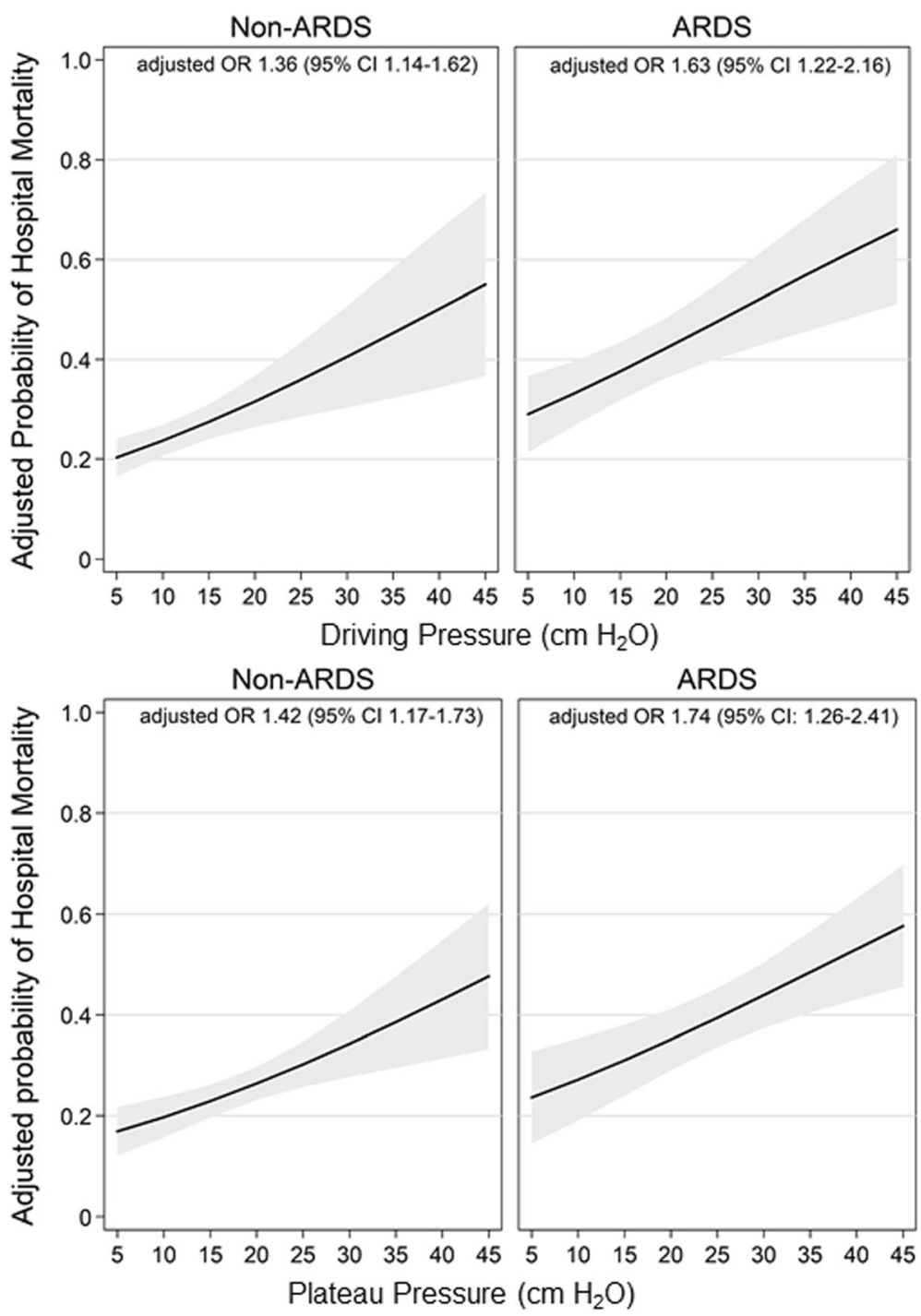

Fig. 4 Predicted probability of hospital mortality by increases in driving pressure and plateau pressure by ARDS status. Adjusted OR for mortality

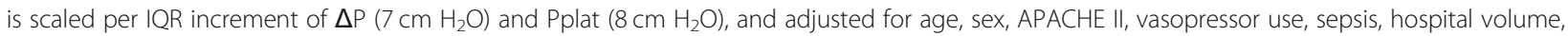
and ICU category

in the low tidal volume group received pressure support ventilation, which permitted large spontaneous tidal volumes outside of the target $6 \mathrm{~mL} / \mathrm{kg}$ PBW. The results of the PReVENT trial highlight the importance of prospectively evaluating alternate lung-protective mechanical ventilation strategies in the non-ARDS population. We suggest future trials should focus on limiting $\Delta \mathrm{P}$ rather than on targeting an absolute tidal volume goal.

Our study has several strengths. First, it is a large prospective cohort study with data from 59 different ICUs, both medical and surgical, geographically dispersed across the USA, which increases the generalizability of our findings. Data were collected prospectively by experienced and trained research coordinators. ARDS status was ascertained prospectively and similarly to how it is determined in a clinical setting. Second, our participants demonstrated wide ranges of $\triangle \mathrm{P}$, Pplat, and PEEP, which allow for evaluation across the spectrum of severity of respiratory failure. Third, we internally validated our dataset by evaluating the association between $\triangle \mathrm{P}$ and ARDS in addition to analyzing the relationship in non-ARDS participants. Finally, our findings are in concordance with other epidemiologic studies suggesting that $\Delta \mathrm{P}$ is associated with clinical outcomes in non-ARDS participants $[9,19]$.

Although our results are significant, our study has some potential shortcomings. One major limitation is that our values for Pplat and $\Delta \mathrm{P}$ were not always derived from the same day of the ICU course across all of the participants. Some participants were enrolled into the study on ICU day 1 , others on day 5 and between, and we do not know 
this distribution of time to intubation to enrollment, which precludes further sensitivity analysis. Needham and colleagues described the importance of timing of lungprotective ventilation and showed that there was a large mortality benefit in starting this earlier rather than later [21]. Misclassification bias could potentially limit our findings as well. Based on enrollment timing, some of the non-ARDS participants may have already starting to develop ARDS contributing to misclassification bias. Alternatively, some of the non-ARDS participants may have developed ARDS after study enrollment, which could have overestimated our non-ARDS mortality and underestimated ARDS mortality. Finally, although ARDS status was prospectively ascertained by trained research coordinators, the diagnosis of ARDS is routinely missed by seasoned clinicians $[16,22]$. A sensitivity analysis, however, confirmed that our findings were robust even when classifying participants by the presence or absence of hypoxemic respiratory failure $\left(\mathrm{PaO}_{2} / \mathrm{FiO}_{2}<300\right)$ rather than diagnosis of ARDS. Nevertheless, many of our non-ARDS participants were relatively hypoxemic with reduced compliance suggesting their lung disease was severe despite the lack of ARDS. Future studies confirming our results will need to standardize the time of airway pressure measurement and consider the longitudinal effect of airway pressures on the risk for mortality and ARDS development.

Another limitation is that the majority of these ICUs were academic which can limit the generalizability of our findings. Furthermore, there were a large number of mechanically ventilated patients who did not have Pplat measured and were excluded from our study. Because our protocol specified obtaining Pplat on all patients if possible, the included patients are presumably different than those who had Pplat measured. Additionally, Pplat and $\Delta \mathrm{P}$ reflect both lung and chest wall compliance and are potentially affected by spontaneous respiratory efforts. In patients who are spontaneously breathing or have altered chest wall compliance, airway pressures are imperfect measures of lung stress, although may still be adequate surrogates [7]. Finally, our study does not prove a causal effect between lower $\Delta \mathrm{P}$ and improved survival in non-ARDS participants. Respiratory system compliance, a major component of $\Delta \mathrm{P}$, is a strong independent predictor of mortality. The complex mathematical and physiologic coupling between $\Delta \mathrm{P}$, compliance, tidal volume, and PEEP further complicates efforts to confirm a causal relationship between $\Delta \mathrm{P}$ and mortality. However, our results add significantly to the body of evidence supporting the need for randomized controlled trials comparing $\Delta \mathrm{P}$-targeted ventilation strategies compared to our current practice of limiting tidal volumes only.

\section{Conclusions}

Our findings demonstrate that greater $\Delta \mathrm{P}$ and Pplat are associated with increased mortality in patients without
ARDS, similar to the findings in patients with ARDS. In mechanically ventilated patients, $\Delta \mathrm{P}$ and Pplat may be useful markers of lung stress. $\Delta \mathrm{P}$ and Pplat demonstrated a linear relationship with odds of mortality, suggesting that lower $\Delta \mathrm{P}$ and Pplat are better. Recent evidence suggests $\triangle \mathrm{P}$ may be a critical target for mechanical ventilation in ARDS patients. $\Delta \mathrm{P}$ can be lowered by reducing tidal volume or by optimizing respiratory system compliance through PEEP titration or proning [23-25]. Future research should prospectively evaluate the feasibility and efficacy of ventilation strategies that limit $\Delta \mathrm{P}$. Based on our results, these ventilation strategies should be evaluated in both ARDS and non-ARDS patient populations.

\section{Supplementary information}

Supplementary information accompanies this paper at https://doi.org/10. 1186/s13054-019-2635-y.

Additional file $\mathbf{1}$ Table S1. Shows baseline characteristics of participants by type of ICU. Table S2. Shows baseline characteristics of participants by controlled versus spontaneous mode of ventilation. Table S3. Shows the proportion of participants receiving each ventilator mode. Table S4. Shows the multivariable logistic regression results from the sensitivity analysis of participants receiving controlled ventilator modes.

\section{Abbreviations \\ ARDS: Acute respiratory distress syndrome; Pplat: Plateau pressure; \\ $\triangle \mathrm{P}$ : Driving pressure; PEEP: Positive end-expiratory pressure; ICU: Intensive care unit; LOS: Length of stay; PBW: Predicted body weight; SCCM: Society of Critical Care Medicine; CIOS: Critical IIIness Outcomes Study; APACHE: Acute Physiologic and Chronic Health Evaluation; SOFA: Sequential Organ Failure Assessment}

\section{Acknowledgements}

None

\section{Authors' contributions}

All authors read and approved the final manuscript. The CIOS investigators contributed to the study concept and design and the acquisition of data. SS, $\mathrm{CM}, \mathrm{RB}$, and WC contributed to the analysis and interpretation of data. SS, CM, and WC contributed to the statistical analysis. SS and CM contributed to the writing of the manuscript. SS, CM, GM, TG, JS, RB, and WC contributed to the critical editing of the content.

\section{Funding}

The research reported in this publication was supported by the National Heart, Lung, and Blood Institute of the National Institutes of Health under award number T32HL007534 (SS and CM) and the Pearl M. Stetler Research Fellowship (SS). Dr. Martin (GM) was supported in part by the NIH under award UL1 TR-000454 (NCATS). The content is solely the responsibility of the authors and does not necessarily represent the official views of the National Institutes of Health.

\section{Availability of data and materials}

The datasets used and/or analyzed during the current study are available from the corresponding author on reasonable request.

\section{Ethics approval and consent to participate}

The CIOS study was approved by the Institutional Review Boards at all participating hospitals (NA_00026710). Waiver of consent was approved by individual Institutional Review Boards. 


\section{Competing interests}

The authors declare that they have no competing interests.

\section{Author details}

'Division of Pulmonary and Critical Care, Johns Hopkins University, $1830 \mathrm{E}$ Monument St Room 555, Baltimore, MD 21287, USA. ²Division of Pulmonary, Allergy, Critical Care, and Sleep Medicine, Emory University, Atlanta, USA. ${ }^{3}$ Grady Health System, Atlanta, GA, USA. ${ }^{4}$ Clinical Research, Investigation, and Systems Modeling of Acute Illness (CRISMA) Center, Department of Critical Care Medicine, University of Pittsburgh School of Medicine, Pittsburgh, USA

Received: 2 January 2019 Accepted: 3 October 2019

Published online: 21 November 2019

\section{References}

1. Dreyfuss D, Saumon G. Ventilator-induced lung injury. Am J Respir Crit Care Med. 1998;157:294-323.

2. Slutsky AS, Ranieri VM. Ventilator-induced lung injury. N Engl J Med. 2013; 369:2126-36.

3. Acute Respiratory Distress Syndrome N, Brower RG, Matthay MA, Morris A, Schoenfeld D, Thompson BT, et al. Ventilation with lower tidal volumes as compared with traditional tidal volumes for acute lung injury and the acute respiratory distress syndrome. N Engl J Med. 2000;342:1301-8.

4. Fan E, Del Sorbo L, Goligher EC, Hodgson CL, Munshi L, Walkey AJ, et al. An official American Thoracic Society/European Society of Intensive Care Medicine/Society of Critical Care Medicine clinical practice guideline: mechanical ventilation in adult patients with acute respiratory distress syndrome. Am J Respir Crit Care Med. 2017;195:1253-63.

5. Amato MB, Meade MO, Slutsky AS, Brochard L, Costa EL, Schoenfeld DA, et al. Driving pressure and survival in the acute respiratory distress syndrome. N Engl J Med. 2015;372:747-55.

6. Baedorf Kassis E, Loring SH, Talmor D. Mortality and pulmonary mechanics in relation to respiratory system and transpulmonary driving pressures in ARDS. Intensive Care Med. 2016;42:1206-13.

7. Chiumello D, Carlesso E, Brioni M, Cressoni M. Airway driving pressure and lung stress in ARDS patients. Crit Care. 2016;20:276.

8. Aoyama H, Pettenuzzo T, Aoyama K, Pinto R, Englesakis M, Fan E. Association of driving pressure with mortality among ventilated patients with acute respiratory distress syndrome: a systematic review and metaanalysis. Crit Care Med. 2018;46:300-6.

9. Neto AS, Hemmes SN, Barbas CS, Beiderlinden M, Fernandez-Bustamante A,

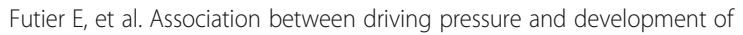
postoperative pulmonary complications in patients undergoing mechanical ventilation for general anaesthesia: a meta-analysis of individual patient data. Lancet Respir Med. 2016:4:272-80.

10. Schmidt MFS, Amaral A, Fan E, Rubenfeld GD. Driving pressure and hospital mortality in patients without ARDS: a cohort study. Chest. 2018;153:46-54.

11. Stewart TE, Meade MO, Cook DJ, Granton JT, Hodder RV, Lapinsky SE, et al. Evaluation of a ventilation strategy to prevent barotrauma in patients at high risk for acute respiratory distress syndrome. Pressure- and volumelimited ventilation strategy group. N Engl J Med. 1998;338:355-61.

12. Ali NA, Gutteridge D, Shahul S, Checkley W, Sevransky J, Martin GS. Critical illness outcome study: an observational study on protocols and mortality in intensive care units. Open Access J Clin Trials. 2011;3:55-65.

13. Bernard GR, Artigas A, Brigham KL, Carlet J, Falke K, Hudson L, et al. The American-European Consensus Conference on ARDS. Definitions, mechanisms, relevant outcomes, and clinical trial coordination. Am J Respir Crit Care Med. 1994;149:818-24.

14. Bellani G, Grassi A, Sosio S, Foti G. Plateau and driving pressure in the presence of spontaneous breathing. Intensive Care Med. 2019:45:97-8.

15. Bellani G, Grasselli G, Teggia-Droghi M, Mauri T, Coppadoro A, Brochard L, et al. Do spontaneous and mechanical breathing have similar effects on average transpulmonary and alveolar pressure? A clinical crossover study. Crit Care. 2016;20:142.

16. Bellani G, Laffey JG, Pham T, Fan E, Brochard L, Esteban A, et al. Epidemiology, patterns of care, and mortality for patients with acute respiratory distress syndrome in intensive care units in 50 countries. JAMA. 2016:315:788-800.

17. Villar J, Martin-Rodriguez C, Dominguez-Berrot AM, Fernandez L, Ferrando C, Soler JA, et al. A Quantile analysis of plateau and driving pressures: effects on mortality in patients with acute respiratory distress syndrome receiving lung-protective ventilation. Crit Care Med. 2017:45:843-50.

18. Simonis FD, Serpa Neto A, Binnekade JM, Braber A, Bruin KCM, Determann $\mathrm{RM}$, et al. Effect of a low vs intermediate tidal volume strategy on ventilatorfree days in intensive care unit patients without ARDS: a randomized clinical trial. JAMA. 2018;320(18):1872-188.

19. Neto AS, Barbas CSV, Simonis FD, Artigas-Raventos A, Canet J, Determann RM, et al. Epidemiological characteristics, practice of ventilation, and clinical outcome in patients at risk of acute respiratory distress syndrome in intensive care units from 16 countries (PRoVENT): an international, multicentre, prospective study. Lancet Respir Med. 2016:4(11):882-93.

20. Neto AS, Simonis FD, Barbas CS, Biehl M, Determann RM, Elmer J, et al. Lung-protective ventilation with low tidal volumes and the occurrence of pulmonary complications in patients without acute respiratory distress syndrome: a systematic review and individual patient data analysis. Crit Care Med. 2015;43:2155-63.

21. Needham DM, Yang T, Dinglas VD, Mendez-Tellez PA, Shanholtz C, Sevransky JE, et al. Timing of low tidal volume ventilation and intensive care unit mortality in acute respiratory distress syndrome. A prospective cohort study. Am J Respir Crit Care Med. 2015;191:177-85.

22. Sjoding MW, Hofer TP, Co I, Courey A, Cooke CR, Iwashyna TJ. Interobserver reliability of the Berlin ARDS definition and strategies to improve the reliability of ARDS diagnosis. Chest. 2018;153:361-7.

23. Sahetya SK, Mancebo J, Brower RG. Fifty years of research in ARDS. Vt selection in acute respiratory distress syndrome. Am J Respir Crit Care Med. 2017:196:1519-25.

24. Retamal J, Libuy J, Jimenez M, Delgado M, Besa C, Bugedo G, et al. Preliminary study of ventilation with $4 \mathrm{ml} / \mathrm{kg}$ tidal volume in acute respiratory distress syndrome: feasibility and effects on cyclic recruitment derecruitment and hyperinflation. Crit Care. 2013;17:R16.

25. Bruhn A, Bugedo D, Riquelme F, Varas J, Retamal J, Besa C, et al. Tidal volume is a major determinant of cyclic recruitment-derecruitment in acute respiratory distress syndrome. Minerva Anestesiol. 2011;77:418-26.

\section{Publisher's Note}

Springer Nature remains neutral with regard to jurisdictional claims in published maps and institutional affiliations.

Ready to submit your research? Choose BMC and benefit from:

- fast, convenient online submission

- thorough peer review by experienced researchers in your field

- rapid publication on acceptance

- support for research data, including large and complex data types

- gold Open Access which fosters wider collaboration and increased citations

- maximum visibility for your research: over $100 \mathrm{M}$ website views per year

At $\mathrm{BMC}$, research is always in progress.

Learn more biomedcentral.com/submission 